Batista, JAS, Barbosa, MS, Silva, FNL, Oliveira, LC \& Sousa, RL. (2020). Social, economic and environmental description of rural communities in Acará, Pará, Brazil. Research, Society and Development, 9(7):1-24, e423974294.

\title{
Descrição social, econômico e ambiental de comunidades rurais no Acará, Pará, Brasil
} Social, economic and environmental description of rural communities in Acará, Pará, Brazil

Descripción social, económica y ambiental de las comunidades rurales en Acará, Pará, Brasil

Recebido: 06/05/2020 | Revisado: 08/05/2020 | Aceito: 11/05/2020 | Publicado: 20/05/2020

José Augusto dos Santos Batista

ORCID: https://orcid.org/0000-0001-5514-3496

Universidade Federal do Pará, Campus Universitário de Abaetetuba, Brasil

E-mail: j.a.s.batista@hotmail.com

Mayane de Souza Barbosa

ORCID: https://orcid.org/0000-0002-9064-9203

Universidade Federal do Pará, Campus Universitário de Abaetetuba, Brasil

E-mail: mayanebarbosa.ufpa@gmail.com

Fabricio Nilo Lima da Silva

ORCID: https://orcid.org/0000-0002-6402-0540 Instituto Federal de Educação, Ciência e Tecnologia do Pará, Campus Breves, Brasil E-mail: fabricio.nilo@ifpa.edu.br

Luã Caldas de Oliveira

ORCID: https://orcid.org/0000-0001-6629-680X Instituto Federal de Educação, Ciência e Tecnologia do Pará, Campus Breves, Brasil E-mail: lua.oliveira@ifpa.edu.br Ronaldo Lopes de Sousa

ORCID: https://orcid.org/0000-0002-5440-2959 Universidade Federal do Pará, Campus Universitário de Abaetetuba, Brasil E-mail: ronaldosousa@ufpa.br

\section{Resumo}

O objetivo do estudo foi traçar o perfil social, econômico e ambiental de comunidades no município do Acará, Pará, Brasil. A pesquisa ocorreu nas comunidades Monte Carmelo do 
Igarapé Retiro, Nazaré do Alto Igarapé Ipitinga, Nazaré do Baixo Igarapé Ipitinga, Roma e Vera Cruz, durante os meses de agosto a novembro de 2019. Foi utilizado um questionário semiestruturado para 65 famílias. Observamos que $71 \%$ dos entrevistados são do sexo/gênero masculino e agricultores. A faixa de idade predominante foi de 31 a 50 anos e $78 \%$ dos entrevistados possuem ensino fundamental completo. A agricultura familiar é praticada sem utilização de adubo e agrotóxicos, pois os produtores sabem do impacto ambiental que podem causar. Entre os vegetais mais cultivados e comercializados está o açaí (Euterpe oleracea Mart.). O rendimento mensal das famílias é proveniente da venda de produtos proveniente da agricultura, além da prática do artesanato e do extrativismo, e recebem benefícios sociais, como o bolsa família e a aposentadoria. Todos os entrevistados afirmam que teve algum problema ambiental nas comunidades. Eles destacaram as mudanças climáticas na região e a contaminação dos igarapés, por efluentes industriais. A produção do óleo dendê foi apontada pelos entrevistados, a principal causa dessa contaminação e alegam que todos os moradores locais tiveram que construir poços artesianos em suas casas, para suprir suas necessidades. Em conclusão, o perfil socioeconômico mostrou um panorama das comunidades e com a introdução de empresa produtora de óleo de dendê na região tem contribuído para mudanças negativas socioambientais, principalmente com a contaminação dos igarapés. Como trabalhos futuros, sugerimos a realização de capacitações em técnicas de tratamento de resíduos sólidos e de efluentes nessas comunidades, com o objetivo de mitigar os impactos ambientais observados no presente estudo.

Palavras-chave: Amazônia; Agricultura; População rural; Caracterização.

\section{Abstract}

The aim of the study was to outline the social, economic and environmental profile of communities in the municipality of Acará, Pará, Brazil. The research took place in the communities of Monte Carmelo do Igarapé Retiro, Nazaré do Alto Igarapé Ipitinga, Nazaré do Baixo Igarapé Ipitinga, Roma and Vera Cruz, from August to November 2019. A semistructured questionnaire was used for 65 families. We observed that $71 \%$ of the interviewees are male and farmers. The predominant age range was 31 to 50 years old and $78 \%$ of the interviewees have completed elementary school. Family farming is practiced without the use of fertilizer and pesticides, as producers are aware of the environmental impact they can cause. Among the most cultivated and commercialized vegetables is açaí (Euterpe oleracea Mart.). The monthly income of families comes from the sale of products from agriculture, in addition to the practice of handicrafts and extraction forest, and receives social benefits, such 
as the family allowance and retirement. All respondents say they had an environmental problem in the communities. They highlighted climate change in the region and the contamination of streams by industrial effluents. The production of palm oil was pointed out by the interviewees, the main cause of this contamination and they claim that all residents had to build artesian wells in their homes, to supply their needs. In conclusion, the socioeconomic profile showed an overview of the communities and the introduction of a palm oil producing company in the region has contributed to negative socio-environmental changes, mainly with the contamination of the streams. As future studies, we suggest training in solid waste and effluent treatment techniques in these communities, with the objective of mitigating the environmental impacts observed in the present study.

Keywords: Amazon; Agriculture; Rural population; Characterization.

\section{Resumen}

El objetivo del estudio fue delinear el perfil social, económico y ambiental de las comunidades en el municipio de Acará, Pará, Brasil. La encuesta se realizó en las comunidades de Monte Carmelo do Igarapé Retiro, Nazaré do Alto Igarapé Ipitinga, Nazaré do Baixo Igarapé Ipitinga, Roma y Vera Cruz, de agosto a noviembre de 2019. Se utilizó un cuestionario semiestructurado para 65 familias. Observamos que el $71 \%$ de los entrevistados son hombres y agricultores. El rango de edad predominante fue de 31 a 50 años y el $78 \%$ de los entrevistados han completado la escuela primaria. La agricultura familiar se practica sin el uso de fertilizantes y pesticidas, ya que los productores son conscientes del impacto ambiental que pueden causar. Entre las verduras más cultivadas y comercializadas se encuentra el açaí (Euterpe oleracea Mart.). El ingreso mensual de las familias proviene de la venta de productos de la agricultura, además de la práctica de la artesanía y la extracción, y recibe beneficios sociales, como la Bolsa Familia y la jubilación. Todos los encuestados dicen que tenían un problema ambiental en las comunidades. Destacaron el cambio climático en la región y la contaminación de las corrientes por efluentes industriales. Los entrevistados señalaron la producción de aceite de palma, la principal causa de esta contaminación, y afirman que todos los residentes locales tuvieron que construir pozos artesianos en sus hogares para satisfacer sus necesidades. En conclusión, el perfil socioeconómico mostró una visión general de las comunidades y la introducción de una empresa productora de aceite de palma en la región ha contribuido a cambios socioambientales negativos, principalmente con la contaminación de las corrientes. Como trabajo futuro, sugerimos llevar a cabo capacitación 
en técnicas para el tratamiento de residuos sólidos y efluentes en estas comunidades, a fin de mitigar los impactos ambientales observados en el presente estudio.

Palabras clave: Amazonia; Agricultura; Población rural; Caracterización.

\section{Introdução}

O dendê é uma palmeira que pertence à família das Arecaceae, do gênero Elaeis, popularmente chamada de "palmeira-de-dendê" que em sua etimologia é oriundo do termo quimbundo ndénde, que significa "palmeira". Originária da África, tendo como centro específico a região do Golfo da Guiné, daí cientificamente a origem de seu nome Elaeis guineensis (Homma, 2016). A cultura do dendê foi introduzida no Brasil no final do século XVI, através do tráfego de escravos africanos. Essa atividade não teve obstáculos frente às condições climáticas da região, por serem semelhantes ao centro de origem.

A dendeicultura é tratada por diferentes abordagens na Amazônia, sendo que algumas destacam as potencialidades econômicas diante de condições edafoclimáticas, que priorizam a produtividade e a rentabilidade (Furlan Jr et al., 2006; Homma \& Vieira, 2012). No estado do Pará, a cultura do dendê predomina na região do Nordeste do estado, sendo que apresenta as maiores áreas cultivadas no Brasil (Venturieri et al., 2009; Nahum; Santos, 2013). De acordo com o Instituto Evandro Chagas (2004) e da organização não governamental Repórter Brasil (2013), destacam vários impactos socioambientais no Pará, com a prática da cultura do dendê. Na região do Baixo Tocantins, no Nordeste Paraense, por exemplo, existem áreas onde há presença de grandes empresas responsáveis pelo monocultivo de dendezeiro que geram resíduos agroindustriais. Vale ressaltar, que tal prática de forma inadequada pode acarretar para a população casos de alergias, irritações cutâneas, contaminação de igarapés, aparecimentos de doenças e até mesmo morte (Chaves \& Magalhães, 2016).

Um dos principais impactos sociais, econômicos e ambientais do dendê já detectados na região, tem sido a contaminação por agrotóxicos e posteriormente por efluentes das agroindústrias de extração de óleo de palma. Muitas das vezes esse é lançado sem tratamento no solo que vão atingindo igarapés que alimentam os inúmeros rios, como o Pará, Tocantins, Moju, Acará, Acará-Mirim, Miritipitanga, Capim, Auiaçu, Maracanã e Camari (BRASIL, 2013). No município de Acará, o rio Acará se destaca, cruzando todo o município de sul a norte, nascendo na Serra dos Coroados, ao sul do município de Tailândia, e d'água em frente a Belém capital do estado na baia do Guajará juntamente com os rios Moju, Guamá e 
Tocantins (Cruz, 2018). Vale destacar, que os rios na Amazônia são de suma importância para diversas finalidades socioeconômicas nesta região. Portanto, investigar os aspectos sociais, econômicos e ambientais, após a chegada de indústrias atuantes na produção de óleo de dendê, torna-se relevante.

Assim, os indicadores socioeconômicos e, ambiental permitem uma visão geral das comunidades na Amazônia, que ajudará no desenvolvimento de estratégias e promoverá o desenvolvimento sustentável local. Diante do exposto, o objetivo do estudo foi traçar o perfil social, econômico e ambiental de comunidades no município do Acará, Pará, Brasil. Esses resultados poderão gerar dados, para promoção de políticas públicas na região do Baixo Tocantins.

\section{Metodologia}

\section{1 Área de estudo}

Pesquisas são realizadas para se alcançar novos saberes como afirma Pereira et al. (2018). Quando ela é realizada em campo, as variáveis são mais complexas e de difícil controle em relação às pesquisas laboratoriais. A presente pesquisa foi conduzida com 219 pessoas representantes de famílias distintas, distribuídas nas Comunidades ou Vilas, como são chamadas: Monte Carmelo do Igarapé Retiro, Nazaré do Alto Igarapé Ipitinga, Nazaré do Baixo Igarapé Ipitinga, Roma e Vera Cruz, no município de Acará, Pará, Brasil (Figura 1).

Figura 1. Localização do município de Acará, Pará, Brasil. Elaborado pelos autores.
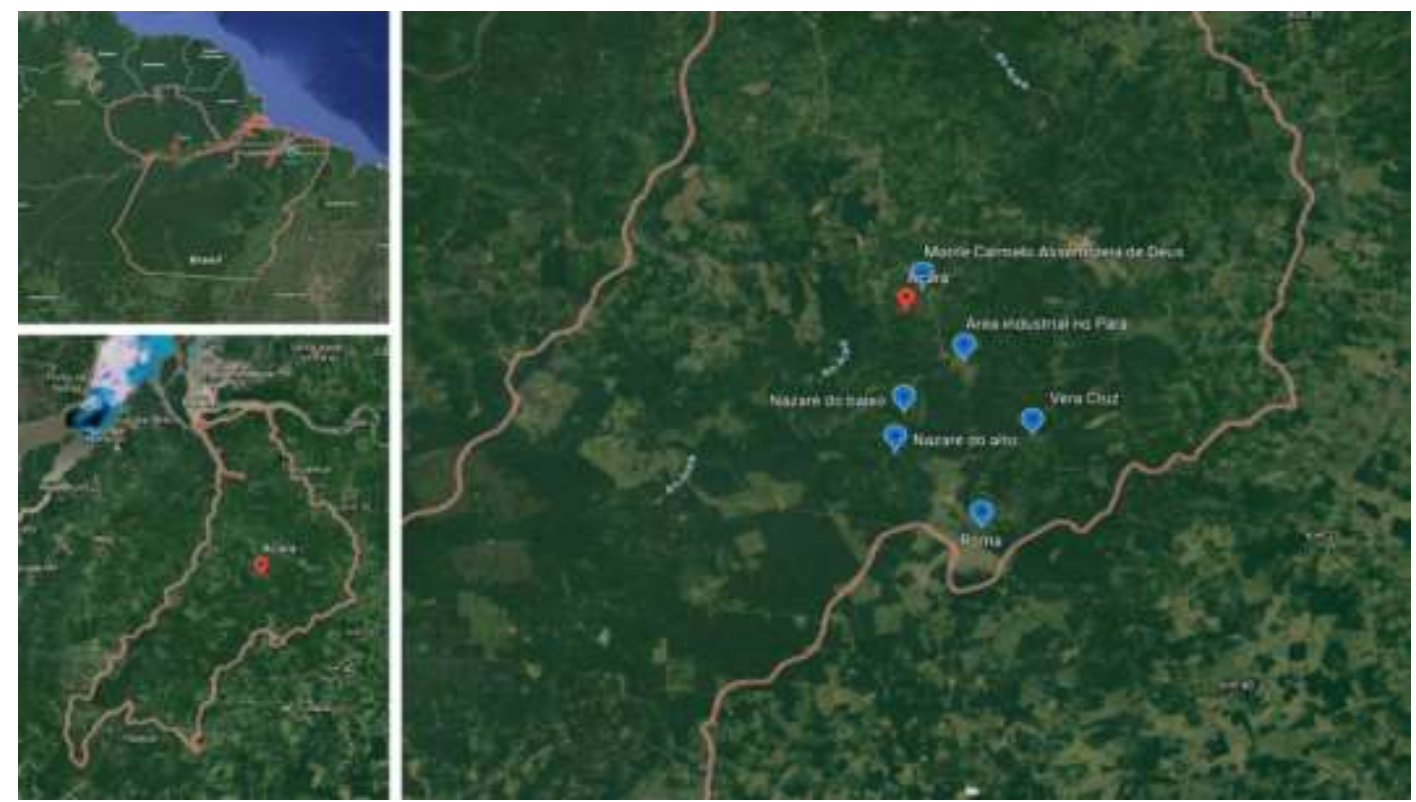

Fonte: Autores. 
Research, Society and Development, v. 9, n. 7, e423974294, 2020

(CC BY 4.0) | ISSN 2525-3409 | DOI: http://dx.doi.org/10.33448/rsd-v9i7.4294

Na Figura 1, as comunidades apresentadas podem ser consideradas uma amostra representativa do município de acará, com relação ao meio ambiente e relevo, formados em função da proximidade com o rio acará. Acará está localizado no nordeste paraense, região do baixo Tocantins, mesorregião de Tomé-Açu. O município possui uma área de 4.363 .3 km², politicamente é constituído da sede e dos distritos de Guajará-Mirim e Jaguarari, e os subdistritos de baixo Acará e Miritipitanga. Limita-se ao norte com os municípios de Belém, Ananindeua e Marituba; a leste com os municípios de Bujaru, Concórdia-do-Pará e ToméAçu; ao sul com Tailândia e a oeste com Moju e Barcarena (Passos, 2002).

Acará é cortado pelo rio do mesmo nome, o que em frente à sede deságua o seu grande afluente, o rio Acará-Mirim. A região é agrícola e com um grande potencial ecológico, atualmente, conta com uma população distribuída em 48 comunidades, morando ás margens de rios e igarapés. Sua economia é baseada no plantio de mandioca (Manihot esculenta), para produção e comercialização de farinha e também da produção do açaí (Euterpe oleracea), pimenta-do-reino (Piper nigrum) e a indústria do dendê (Elaeis guineensis).

A Tabela 1 mostra o universo das famílias estudadas por comunidades no Acará.

Tabela 1. Quantitativo de famílias pesquisadas no município de Acará, Pará, Brasil.

Comunidade

\begin{tabular}{lc|c}
\hline \multicolumn{1}{c}{ Comunidade } & \multicolumn{2}{c}{ Quantitativo de famílias $^{\mathbf{1}}$} \\
\cline { 2 - 3 } & $\begin{array}{r}\text { Total de famílias } \\
\text { das comunidades }\end{array}$ & $\begin{array}{c}\text { Total de famílias que se aplicou } \\
\text { questionários, equivalente 30\% de } \\
\text { cada comunidade estudada }\end{array}$ \\
\hline Comunidade/Vila Vera Cruz & 85 & 25 \\
Comunidade/Vila Roma & 23 & 07 \\
Comunidade/Vila Nazaré do Baixo & 51 & 15 \\
Comunidade/Vila Nazaré do Alto & 42 & 13 \\
Comunidade/Vila Monte Carmelo & 18 & 05 \\
\hline Total & $\mathbf{2 1 9}$ & $\mathbf{6 5}$ \\
\hline
\end{tabular}

${ }^{1}$ Segundo os Agentes Comunitários de Saúde de cada comunidade.

Fonte: Coleta de campo. 


\subsection{Coleta e análise de dados}

O percurso metodológico consistiu na pesquisa qualitativa e quantitativa. A primeira foi de natureza exploratória, que tem como procedimentos básicos para sua execução a pesquisa bibliográfica e documental. A investigação qualitativa requer como atitudes fundamentais a abertura, a flexibilidade, a capacidade de observação e de interação com o grupo de investigadores e com os atores sociais envolvidos (Mynaio, 2004).

Para quantitativa, foi utilizado um questionário para coleta de dados, com três itens principais: a) Perfil social, que contemplou os seguintes temas: gênero, naturalidade, estado civil, faixa etária, número de pessoas por residência, número de filhos, tempo residente na localidade, grau de escolaridade; b) Perfil econômico, que considerou a renda (financiamento/empréstimo), se há aposentados pensionistas ou se houve algum benefício social como bolsa família e outros, qual foi a principal atividade econômica, renda derivada do extrativismo e organização associativa local e c) Perfil ambiental das comunidades estudas para identificar os impactos socioambientais causada pelas indústrias locais, que foi implantado no Acará. A entrevista é um encontro entre pessoas, a fim de que uma delas obtenha informações a respeito de determinado assunto, mediante uma conversação de natureza profissional (Marconi \& Lakatos, 2010).

O método de amostragem utilizado foi do tipo não-probabilístico e classificada como snow-ball (bola de neve), na qual o primeiro entrevistado aponta o próximo, e assim sucessivamente, observando os critérios definidos pelo pesquisador (Silva et al., 2011). As identidades dos participantes foram mantidas em sigilo, garantindo seu anonimato e confidencialidade das informações. Os dados levantados foram agrupados e tabulados no Microsoft Office Excel e analisados usando estatística descritiva (Zar, 1999).

\section{Resultados e Discussão}

\subsection{Perfil social}

No presente estudo, foi observado uma maior (71\%) participação de homens (Tabela 2). Embora a porcentagem de mulheres seja baixa (29\%), destacamos que elas tem participação crescente nas atividades rurais no decorrer dos anos, saindo do anonimato e adquirindo visibilidade no Baixo Tocantins. As mulheres realizam tarefas econômicas familiares, sobretudo no que tange ao trabalho nas comunidades. Maneschy (1995) ressalta 
que na Amazônia as mulheres dividem seu tempo com as responsabilidades tradicionais no espaço doméstico, como cuidar dos filhos e da casa, além de terem grande representatividade em tarefas que normalmente são direcionadas ao sexo masculino, tais como: a pesca, o plantio e a colheita para consumo e sustento da família. No Acará, não é diferente, elas estão envolvidas em todas as atividades nas comunidades.

Detectamos que todos os indivíduos nasceram no estado do Pará, a maioria (31\%) possuíam idades acima de 30 anos (Tabela 2). Nota-se, em relação à idade das pessoas entrevistadas, pouco envolvimento dos jovens. Este fato provavelmente ocorreu, pelo fato de os jovens entenderem que seus pais podem passar mais informações do que eles, visto que estes, tem mais experiência de vida, e também pelo pouco envolvimento dos jovens nas atividades rurais, que muitas das vezes migram para as cidades, em busca de novas oportunidades, conforme foi observado por Cavalheiro et al. (2014). Na Amazônia, a nova geração, tem saído do meio rural, seja por falta de terra quanto de vocação ou aspiração, buscando o emprego, a educação, a saúde e o consumo nas cidades da região ou mesmo em outras partes do Brasil (UNFPA, 2015).

Tabela 2. Perfil social por comunidade/vila no município de Acará, Pará, Brasil.

\begin{tabular}{|c|c|c|c|c|c|c|c|}
\hline Perfil social dos entrevistados & $\begin{array}{l}\text { Vera } \\
\text { Cruz }\end{array}$ & $\begin{array}{c}\text { Vila } \\
\text { Roma }\end{array}$ & $\begin{array}{c}\text { Nazaré } \\
\text { do Baixo }\end{array}$ & $\begin{array}{l}\text { Nazaré } \\
\text { do Alto }\end{array}$ & $\begin{array}{c}\text { Monte } \\
\text { Carmelo }\end{array}$ & $\mathbf{F A}^{1}$ & $\operatorname{FR}(\%)^{2}$ \\
\hline \multicolumn{8}{|l|}{ Gênero } \\
\hline Masculino & 18 & 7 & 10 & 7 & 4 & 46 & $71 \%$ \\
\hline Feminino & 7 & 0 & 5 & 6 & 1 & 19 & $29 \%$ \\
\hline \multicolumn{8}{|l|}{ Grupo de idade } \\
\hline Menos de 30 anos & 2 & 0 & 1 & 2 & 1 & 6 & $9 \%$ \\
\hline $31-40$ anos & 7 & 2 & 3 & 5 & 3 & 20 & $31 \%$ \\
\hline 41-50 anos & 7 & 3 & 7 & 2 & 0 & 19 & $29 \%$ \\
\hline 51-60 anos & 4 & 0 & 2 & 2 & 0 & 8 & $12 \%$ \\
\hline Mais de 61 anos & 5 & 2 & 2 & 2 & 1 & 12 & $19 \%$ \\
\hline \multicolumn{8}{|l|}{ Escolaridade } \\
\hline Analfabetos & 3 & 1 & 1 & 1 & 1 & 7 & $11 \%$ \\
\hline Ensino Fund. $1^{\circ}$ a $5^{\mathrm{a}}$ ano & 9 & 4 & 7 & 5 & 2 & 27 & $41 \%$ \\
\hline Ensino Fund. $6^{\circ}$ a $9^{a}$ ano & 4 & 1 & 5 & 4 & 0 & 14 & $21 \%$ \\
\hline Ensino Médio & 8 & 1 & 2 & 1 & 2 & 14 & $22 \%$ \\
\hline Ensino Superior & 1 & 0 & 0 & 2 & 0 & 3 & $5 \%$ \\
\hline \multicolumn{8}{|l|}{ Tipos de categorias trabalhistas } \\
\hline Somente Agricultores & 9 & 7 & 13 & 11 & 5 & 45 & $60 \%$ \\
\hline Agricultores/ Funcionários públicos & 5 & 1 & 2 & 3 & 0 & 11 & $14 \%$ \\
\hline Agricultores / Funcionários privados & 3 & 0 & 0 & 0 & 0 & 3 & $4 \%$ \\
\hline Agricultores /Aposentados & 5 & 1 & 1 & 4 & 0 & 11 & $15 \%$ \\
\hline Agricultores / Comerciante e outros & 3 & 0 & 1 & 1 & 0 & 5 & $7 \%$ \\
\hline \multicolumn{8}{|l|}{ Número de pessoas por família } \\
\hline $2-4$ pessoas & 9 & 4 & 7 & 3 & 2 & 25 & $42 \%$ \\
\hline $5-6$ pessoas & 5 & 2 & 4 & 6 & 3 & 20 & $33 \%$ \\
\hline $7-8$ pessoas ou mais & 6 & 1 & 4 & 4 & 0 & 15 & $25 \%$ \\
\hline \multicolumn{8}{|l|}{ Número de filhos } \\
\hline 1 filho & 2 & 0 & 3 & 1 & 0 & 6 & $10 \%$ \\
\hline 2 filhos & 6 & 4 & 4 & 4 & 1 & 19 & $30 \%$ \\
\hline 3 filhos & 5 & 1 & 4 & 2 & 2 & 14 & $22 \%$ \\
\hline 4 a 5 filhos & 5 & 1 & 2 & 3 & 1 & 12 & $19 \%$ \\
\hline
\end{tabular}


Research, Society and Development, v. 9, n. 7, e423974294, 2020

(CC BY 4.0) | ISSN 2525-3409 | DOI: http://dx.doi.org/10.33448/rsd-v9i7.4294

\begin{tabular}{|c|c|c|c|c|c|c|c|}
\hline 6 a 7 filhos & 2 & 1 & 1 & 2 & 1 & 7 & $11 \%$ \\
\hline 8 ou mais filhos & 3 & 0 & 1 & 1 & 0 & 5 & $8 \%$ \\
\hline \multicolumn{8}{|c|}{ Participa de organização social } \\
\hline Sim & 25 & 7 & 15 & 13 & 5 & 65 & $100 \%$ \\
\hline Não & 0 & 0 & 0 & 0 & 0 & 0 & $0 \%$ \\
\hline \multicolumn{8}{|c|}{ Tipos de organização social } \\
\hline Sindicato dos T. R. & 7 & 6 & 10 & 11 & 2 & 36 & $55 \%$ \\
\hline Associação & 8 & 0 & 14 & 10 & 0 & 32 & $49 \%$ \\
\hline Igrejas & 25 & 7 & 15 & 13 & 5 & 65 & $100 \%$ \\
\hline \multicolumn{8}{|c|}{ Religião ou denominação Cristã } \\
\hline Católicos & 4 & 7 & 15 & 11 & 0 & 37 & $65 \%$ \\
\hline Evangélicos & 21 & 0 & 0 & 2 & 5 & 28 & $35 \%$ \\
\hline Outras & 0 & 0 & 0 & 0 & 0 & 0 & $0 \%$ \\
\hline \multicolumn{8}{|c|}{ Padrão da construção de sua residência } \\
\hline Alvenaria & 14 & 2 & 6 & 5 & 2 & 29 & $45 \%$ \\
\hline Madeira & 11 & 5 & 9 & 8 & 3 & 36 & $55 \%$ \\
\hline \multicolumn{8}{|c|}{ Qual a fonte de água para beber } \\
\hline Poço artesiano & 25 & 7 & 15 & 13 & 5 & 65 & $100 \%$ \\
\hline Igarapé / cacimba. & 0 & 0 & 0 & 0 & 0 & 0 & $0 \%$ \\
\hline \multicolumn{8}{|l|}{ Banheiro /sanitário } \\
\hline Fossa Séptica & 17 & 5 & 12 & 8 & 1 & 43 & $34 \%$ \\
\hline Fossa rudimentar negra & 8 & 2 & 3 & 5 & 4 & 22 & $66 \%$ \\
\hline \multicolumn{8}{|l|}{ Fonte de energia utilizada } \\
\hline Energia elétrica & 25 & 7 & 15 & 13 & 5 & 65 & $100 \%$ \\
\hline Gerador a diesel & 0 & 0 & 0 & 0 & 0 & 0 & $0 \%$ \\
\hline Lamparina & 0 & 0 & 0 & 0 & 0 & 0 & $0 \%$ \\
\hline
\end{tabular}

${ }^{1}$ FA. Frequência absoluta. ${ }^{2}$ FR. Frequência relativa.

Fonte: Coleta de campo.

Um total de $89 \%$ dos indivíduos entrevistados nas comunidades estudadas, completou o ensino fundamental $\left(1^{\circ}\right.$ a $5^{\mathrm{a}}$ ano $)$ e $11 \%$ deles não tiveram nenhum estudo, sendo considerados analfabetos. Estes dados, são interessantes, pois a aquisição de conhecimentos pode levar as pessoas a questionar sobre o que vem ocorrendo em sua volta e tentar buscar soluções para estas questões. Por outro lado, os que não tiveram a oportunidade de estudar, foi devido provavelmente as condições mínimas de educação oferecidas nas comunidades locais:

[...] a escola no meio rural esteve sempre sujeita a interesses políticos e econômicos, sem considerar as reais necessidades da população ou dos professores. Isso fez com que o camponês recebesse uma escola de segunda mão (Beltrame, 2000, p. 24).

A pesquisa revelou que somente a comunidade Vera Cruz possui uma escola que atende da educação infantil ao $9^{\circ}$ ano do ensino fundamental. Enquanto que as comunidades Vila de Roma, Nazaré do Baixo e Nazaré do Alto, só oferecem da educação infantil ao $5^{\circ}$ ano do ensino fundamental. Identificamos que a comunidade Monte Carmelo do Igarapé Retiro não possui escola. Dessa forma, os estudantes são obrigados a se deslocarem para outras comunidades próximas para cursarem ou concluírem o ensino Fundamental.

Em relação ao Ensino Médio, 22\% dos entrevistados relatou ter concluído, isso por conta de que os alunos moradores das comunidades Nazaré do Baixo e Nazaré do Alto 
estudam atualmente em uma escola de outra comunidade denominada Santa Bárbara, que oferece o Ensino Fundamental completo e o "SOMEM" (Sistema Organizacional Modula de Ensino Médio). Enquanto que as demais comunidades, a maioria desses alunos tem que ir cursar o Ensino Médio na cidade sedes do município de Acará, conforme relatado pelos entrevistados. Destacaram também as dificuldades em ir para a escola e dividir seu tempo entre o trabalho na comunidade (agricultura) e as atividades escolares, e que também há muito transtorno por conta do transporte escolar ou os ramais de acesso que estão muitas em condições precárias:

A instituição das Diretrizes Operacionais para a Educação Básica nas Escolas do Campo (Resolução CNE/CEB 1/03/2002), implementadas pelo Ministério da Educação, significou um passo importante para o reconhecimento de uma política que valoriza as especificidades do campo. No seio dessa proposta, aparece uma concepção de campo que ultrapassa as históricas e equivocadas propostas do ruralismo pedagógico, nas quais a Educação Rural associa-se a concepção de atraso que orientou as políticas ao longo de quase todo século XX (Souza, 2006, p. 23)

Enquanto que o Ensino Superior, 5\% dos entrevistados chegou a cursa essa modalidade, por conta de todas as dificuldades já relatadas e por só haver Universidade ou Faculdade nas cidades sede e com poucas opções de cursos. Observamos que esses são professores formados em curso de pedagogia, o qual é o de mais acessibilidade.

Em relação a caracterização de trabalho foi evidenciado que $100 \%$ dos entrevistados declararam ser agricultor familiar, embora esta atividade possa também estar associada a outros tipos de trabalho para ganho de suas rendas. Em referência a composição familiar, 75\% dos entrevistados possuem até 6 pessoas vivendo em suas residências. Um total de $62 \%$ dos entrevistados possuem até 3 filhos e $38 \%$ tem 4 ou mais filhos possuindo em média 2 filhos. Estes números de pessoas, pode estar relacionado com a idade dos entrevistados, porque antigamente era costume se ter mais filhos, fato este que não é observado na atualidade, onde a maioria dos casais optam por terem até 3 filhos. Em uma pesquisa com moradores de pequenas comunidades da Amazônia, Caldas et al. (2003) verificaram um tamanho médio da família de 7,12 indivíduos, estando este número dentro do verificado neste trabalho.

A atuação nas organizações de classes é representativa, em nosso estudo todos os entrevistados relataram participar de algum tipo de organização, seja ela sindical ou associações. Observamos que todos estão envolvidos nas igrejas, seja ela católica (65\%) ou evangélica (35\%). Assim, as organizações sociais atendem também as necessidades básicas das pessoas nas comunidades (Brito \& Maciel, 2015; Santos et al., 2017; Soares et al., 2019). 
Portanto, a implantação de formas de organização social, deve ser incentivada e implantada nas comunidades. No Acará, está representada por $49 \%$ associações, e podem ser uma alternativa viável para superação de entraves e gerar benefícios para todos.

Em relação à religião, foi possível observar que as comunidades Vera Cruz e Monte Carmelo, possuem uma grande proporção de evangélicos. De acordo com relato de moradores, o fator que mais contribuiu para o desenvolvimento do Vilarejo no segundo período foi à chegada de pessoas da denominação da igreja evangélica, sendo realizada a posterior construção da igreja e evangelização dos habitantes dessa região, que se tornaram adeptos a esta denominação Cristã.

No que diz respeito ao tipo de moradia, a maioria das casas são feitas de madeira (55\%) e alvenaria (45\%). Em comunidade amazônicas, é muito comum a construção de casa de madeira, em função do baixo custo e ampla disponibilidade na região.

\subsection{Perfil econômico}

Em relação a produção agrícola realizada nas comunidades, $77 \%$ são destinados para venda em feiras e ao consumo (Tabela 3). Um total de $78 \%$ dos entrevistados não utilizam adubação e 55\% não tem nenhum tipo de problema com suas plantações. Nas comunidades, a prática da agricultura familiar é de suma importância na geração de renda e de absorção de mão de obra no campo. Vale considerar que auxilia na redução da migração do campo para a cidade, bem como influencia na segurança alimentar e na preservação ambiental. Portanto, desempenha um papel fundamental para o crescimento da economia local e melhoria das condições de vida das populações (Ahlert, 2015).

Tabela 3. Perfil econômico por comunidade/vila no município de Acará, Pará, Brasil.

\begin{tabular}{|c|c|c|c|c|c|c|c|}
\hline Perfil econômico das comunidades & $\begin{array}{l}\text { Vera } \\
\text { Cruz }\end{array}$ & $\begin{array}{c}\text { Vila } \\
\text { Roma }\end{array}$ & $\begin{array}{c}\text { Nazaré } \\
\text { do Baixo }\end{array}$ & $\begin{array}{l}\text { Nazaré } \\
\text { do Alto }\end{array}$ & $\begin{array}{c}\text { Monte } \\
\text { Carmelo }\end{array}$ & $\mathbf{F A}^{\mathbf{1}}$ & FR $(\%)^{2}$ \\
\hline \multicolumn{8}{|l|}{ Destino da produção agrícola } \\
\hline Consumo & 5 & 0 & 3 & 3 & 0 & 11 & $17 \%$ \\
\hline Venda e consumo & 16 & 7 & 12 & 10 & 5 & 50 & $77 \%$ \\
\hline Não produz & 4 & 0 & 0 & 0 & 0 & 4 & $6 \%$ \\
\hline \multicolumn{8}{|l|}{ Tipos de cultivos } \\
\hline Cultivo misto & 19 & 7 & 15 & 13 & 4 & 58 & $89 \%$ \\
\hline Monocultivo & 0 & 0 & 0 & 0 & 0 & 0 & $0 \%$ \\
\hline Sistema Agroflorestal & 2 & 0 & 0 & 0 & 1 & 3 & $5 \%$ \\
\hline Não cultiva & 4 & 0 & 0 & 0 & 0 & 4 & $6 \%$ \\
\hline \multicolumn{8}{|l|}{ Principais cultivos } \\
\hline Mandioca & 17 & 7 & 15 & 13 & 5 & 57 & $88 \%$ \\
\hline Açaí & 15 & 7 & 14 & 11 & 4 & 51 & $78 \%$ \\
\hline Milho & 10 & 7 & 11 & 11 & 4 & 43 & $66 \%$ \\
\hline Cupuaçu & 11 & 7 & 13 & 6 & 1 & 26 & $40 \%$ \\
\hline
\end{tabular}


Research, Society and Development, v. 9, n. 7, e423974294, 2020

(CC BY 4.0) | ISSN 2525-3409 | DOI: http://dx.doi.org/10.33448/rsd-v9i7.4294

\begin{tabular}{|c|c|c|c|c|c|c|c|}
\hline Pimenta do reino & 4 & 2 & 5 & 5 & 3 & 19 & $29 \%$ \\
\hline Dendê & 2 & 0 & 0 & 1 & 0 & 3 & $5 \%$ \\
\hline Não cultiva & 4 & 0 & 0 & 0 & 0 & 4 & $6 \%$ \\
\hline \multicolumn{8}{|l|}{ Método de adubação } \\
\hline Químico e orgânico & 6 & 2 & 4 & 2 & 3 & 17 & $26 \%$ \\
\hline Não uso & 19 & 5 & 11 & 11 & 2 & 48 & $78 \%$ \\
\hline \multicolumn{8}{|l|}{ Problema com as culturas anuais } \\
\hline Pragas & 0 & 0 & 2 & 1 & 0 & 3 & $5 \%$ \\
\hline Doenças na (mandioca) & 6 & 5 & 6 & 6 & 1 & 24 & $37 \%$ \\
\hline Não ouve. & 19 & 2 & 8 & 7 & 0 & 36 & $55 \%$ \\
\hline \multicolumn{8}{|l|}{ Desenvolve atividades de criação } \\
\hline Sim & 17 & 7 & 15 & 12 & 4 & 55 & $85 \%$ \\
\hline Não & 8 & 0 & 0 & 1 & 1 & 10 & $15 \%$ \\
\hline \multicolumn{8}{|l|}{ Qual o destino da criação } \\
\hline Consumo & 12 & 5 & 8 & 10 & 3 & 38 & $69 \%$ \\
\hline Consumo e Venda & 4 & 2 & 6 & 3 & 2 & 17 & $31 \%$ \\
\hline \multicolumn{8}{|l|}{ Principais tipos de criação } \\
\hline Galinha caipira & 12 & 7 & 15 & 12 & 3 & 49 & $75 \%$ \\
\hline Porco & 4 & 4 & 11 & 5 & 3 & 27 & $42 \%$ \\
\hline Boi ou búfalo & 2 & 1 & 6 & 5 & 1 & 15 & $23 \%$ \\
\hline Pato & 1 & 0 & 2 & 3 & 0 & 6 & $9 \%$ \\
\hline Peru & 2 & 0 & 2 & 1 & 1 & 6 & $9 \%$ \\
\hline Peixes & 3 & 0 & 3 & 1 & 0 & 7 & $11 \%$ \\
\hline Não tem criaçãa & 8 & 0 & 0 & 0 & 1 & 9 & $14 \%$ \\
\hline \multicolumn{8}{|c|}{ Destino da comercialização da produção } \\
\hline Venda direta ao consumidor & 0 & 0 & 0 & 0 & 0 & 0 & $0 \%$ \\
\hline Cooperativa/associação & 0 & 0 & 0 & 0 & 0 & 0 & $0 \%$ \\
\hline Atravessador/Feira municipal & 21 & 7 & 15 & 13 & 5 & 61 & $98 \%$ \\
\hline Outros & 0 & 0 & 0 & 0 & 0 & 0 & $0 \%$ \\
\hline \multicolumn{8}{|c|}{ Principais dificuldade na comercialização da produção. } \\
\hline Preço baixo & 19 & 7 & 14 & 11 & 5 & 56 & $82 \%$ \\
\hline Atravessador & 2 & 0 & 5 & 1 & 0 & 8 & $12 \%$ \\
\hline Outros & 0 & 0 & 2 & 2 & 0 & 4 & $6 \%$ \\
\hline \multicolumn{8}{|l|}{ Renda mensal } \\
\hline Menos até um salário mínimo & 6 & 2 & 7 & 9 & 3 & 27 & $42 \%$ \\
\hline Mais de um até dois salário min. & 11 & 4 & 7 & 2 & 2 & 26 & $40 \%$ \\
\hline Mais de dois salário mínimo. & 8 & 1 & 1 & 2 & 0 & 12 & $18 \%$ \\
\hline \multicolumn{8}{|c|}{ Trabalha em alguma outra atividade remunerada além de sua agricultura } \\
\hline Sim & 12 & 1 & 3 & 4 & 0 & 20 & $31 \%$ \\
\hline Não & 13 & 6 & 12 & 9 & 5 & 45 & $69 \%$ \\
\hline \multicolumn{8}{|c|}{ Algum membro de sua família trabalha fora do seu lote e recebe alguma remuneração em dinheiro ao mês } \\
\hline Sim & 2 & 0 & 5 & 3 & 0 & 10 & $15 \%$ \\
\hline Não & 23 & 7 & 10 & 10 & 5 & 55 & $85 \%$ \\
\hline \multicolumn{8}{|c|}{ Algum membro de sua família recebe algum beneficio } \\
\hline Bolsa família & 11 & 3 & 11 & 9 & 3 & 37 & $57 \%$ \\
\hline Aposentadoria/pensão & 7 & 2 & 3 & 7 & 1 & 20 & $31 \%$ \\
\hline Outros & 0 & 0 & 0 & 0 & 0 & 0 & $0 \%$ \\
\hline Não recebe. & 8 & 2 & 2 & 3 & 1 & 16 & $25 \%$ \\
\hline \multicolumn{8}{|c|}{ Já fez nos últimos dois anos investimentos, créditos, empréstimos para investir em sua produção } \\
\hline Sim & 3 & 0 & 2 & 2 & 1 & 8 & $12 \%$ \\
\hline Não & 22 & 7 & 13 & 11 & 4 & 57 & $88 \%$ \\
\hline \multicolumn{8}{|c|}{ Já teve nos últimos dois anos algum apoio técnico ou políticas públicas } \\
\hline Sim & 3 & 0 & 2 & 2 & 0 & 7 & $11 \%$ \\
\hline Não & 22 & 7 & 13 & 11 & 5 & 58 & $89 \%$ \\
\hline
\end{tabular}

${ }^{1}$ FA. Frequência absoluta. ${ }^{2}$ FR. Frequência relativa.

Fonte: Coleta de campo.

Podemos observar que dos 65 questionários aplicados nas comunidades pesquisadas que a base do cultivo e da produção econômica está focada principalmente na produção de farinha de mandioca (88\%) e também do açaí que gerou uma porcentagem de $78 \%$. Observamos que ocorrem em menor proporção à produção de outros produtos como milho, 
cupuaçu, pimenta-do-reino e dendê. De acordo com os moradores, o cultivo da mandioca para produção da farrinha faz parte da cultura do povo Acaraense. Cultura essa que adquiriram como herança dos seus antepassados indígenas, que pode ser observado em toda a região da Amazônia paraense.

O Acará já foi considerado uns dos maiores produtores de farinha de mandioca do Pará. Essa cultura tem uma grande importância social e econômica para milhares de famílias distribuídas em inúmeras comunidades da região do Pará. Alves e Cardoso (2008) destacam que a maioria dos agricultores do Acará tem seu sustento advindo do cultivo da mandioca e da produção de farinha que representa $80 \%$ da renda familiar. Estimasse que $85 \%$ da produção de farinha de mandioca do município de Acará é para comercialização e 15\% destinado ao consumo familiar. Nahum e Santos (2013), destacam que essa cultura é fundamental na composição da dieta alimentar nas comunidades.

A farinha acompanha tudo que o caboclo come. Tudo tem farinha, todo comporta o pão da terra, como se referiam os primeiros colonos diante do alimento tão novo e desconhecido. De exclusividade indígena, a farinha ganha os caldos de peixe da cozinha portuguesa. Integra decisivamente o cardápio do africano no Brasil, chegando ao popular pirão caboclo (Fraxe, 2004, p. 191).

Outro alimento que também é de grande destaque na vida das comunidades do município de Acará é o Açaí. Observamos que o açaí juntamente com a farinha de mandioca é indispensável na dieta das famílias das comunidades estudadas. Além disso, o açaí é um produto que pode ser considerado de grande importância na cultura local, e devido seus valores nutricionais. O consumo desse alimento vem crescendo no Brasil e no mundo, transformando-se na fruta símbolo do estado, desenvolvendo economicamente a região e gerando renda as populações a nível local e de boa lucratividade (Pagliarussi, 2010).

O tamanho médio das propriedades dos agricultores das comunidades pesquisadas é de aproximadamente 25 hectares, nos quais além da mandioca. Observamos que cultivam o açaí, o milho, o cupuaçu, a pimenta do reino, a pupunha e diversas outras frutas, em sistema de SAFs, "Sistemas Agroflorestais". Nesse sistema, a mão de obra predominante é da família e a força de trabalho é manual. Alguns agricultores possuem cavalos ou búfalos que servem de força de tração no transporte da mandioca, sendo que segundo alguns relatos, esse processo vem sendo substituído por motocicletas.

Por outro lado, vale destacar que a produção de dendê pelas comunidades é a menos representativa, com apenas $5 \%$ do total da produção agrícola das comunidades. Segundo 
estudos que vem sendo realizados pela EMBRAPA Amazônia Oriental, mais precisamente no nordeste paraense na microrregião de Tomé-Açu, possui um grande potencial para a produção do cultivo do dendê devido ter um clima propicio semelhante o seu local de origem na África. Porém, o cultivo desta espécie tem sido realizado em sua maior parte pelas empresas privadas. Fato este que se deve principalmente por ser tratar de uma planta perene, ou seja, demora de 3 a 7 anos para produzir seus frutos, e por outro lado, também por ser considerada de difícil manejo (ABRAPALMA, 2014).

Foi verificado que em $90 \%$ das famílias entrevistadas há criação de galinhas caipiras em seus quintais. Demais espécies têm pouca representatividade. Destes animais, 60\% são para a subsistências e 40\% para a comercialização. De acordo com Sales (2005), a maioria das propriedades rurais criam galinhas em seus quintais, isso porque a espécie se adapta fácil em qualquer ambiente, não ocupando espaço, é de fácil manutenção e, ainda na maioria das vezes ainda se alimenta de restos e insetos disponíveis na propriedade. De acordo com Nahum (2011), faz parte da tradição das comunidades rurais da Amazônia cultivar, criar, extrair e produzir seus alimentos, e vender na beira da cidade como popularmente se denomina a área comercial das cidades ribeirinhas da Amazônia paraense, assim como, a cidade de Acará que também é constituída como cidade ribeirinha.

Existem algumas pessoas na comunidade que são comerciantes ou marreteiros, e há também aposentados e funcionários públicos municipais e estaduais, outras que são empregados da empresa de dendeicultura os que trabalham como funcionários públicos são os trabalhadores das escolas como professores e demais funcionários, além dos agentes comunitários de saúde, os trabalhadores da empresa desenvolve as funções no campo cuidando dos plantios de dendê da empresa.

O trabalho nos plantios de dendê requer muita mão de obra nos vastos plantios da monocultura de dendê no campo, fazendo com quer este trabalhador não encontre tempo para desenvolver a função de agricultor de sua propriedade, vindo a diminuir a produção agrícola da comunidade, como o tradicional cultivo da mandioca. Os agricultores dessas comunidades reproduziam o modo de vida típico do camponês tradicional, no qual o roçado é itinerante, de derruba e queima seguida do pousio da terra de três a quatro anos.

A roça é o local onde produziam seus principais gêneros alimentícios, onde as pessoas mobilizam membros da família e da comunidade, através da troca de dias e na organização de mutirão, realizando o cultivo de mais de uma espécie de produtos numa determinada área, consorciamento da mandioca com o milho, arroz, banana, batata doce, mamão, legumes como o jambu, cariru, jongome, maxixe, quiabo, tomates, pimentinha de 
cheiro, jerimum, e outros como do feijão com a pimenta-do-reino, melancia, abacaxi, do cupuaçu com coco da praia e laranja, do cacau com o açaí e castanha do Pará, dentre outras. A coleta de frutos e sementes da floresta como a castanha-do-Pará, uxi, mari e pequi, juntamente com a caça e a pesca complementam a dieta alimentar dos camponeses conhecidos também como caboclos paraense, agricultores das comunidades pesquisadas no município de Acará.

\subsection{Perfil ambiental}

Em relação aos problemas ambientais, $100 \%$ dos entrevistados declararam que já tiveram algum tipo de problema ambiental nos últimos dois anos (Tabela 4). Nesse sentido, os problemas mais citados foram as mudanças climáticas entre as estações inverno e verão (100\%) que de acordo com os entrevistados quando era pra chover faz sol com alta temperatura e quando era pra fazer sol chove muito, afetando o ciclo da agrícola. Um total de 98\% dos entrevistados citaram também a poluição por efluentes da agroindústria do dendê.

Tabela 4. Perfil ambiental por comunidade/vila no município de Acará, Pará, Brasil.

\begin{tabular}{|c|c|c|c|c|c|c|c|}
\hline Perfil ambiental das comunidades & $\begin{array}{l}\text { Vera } \\
\text { Cruz }\end{array}$ & $\begin{array}{l}\text { Vila } \\
\text { Roma }\end{array}$ & $\begin{array}{l}\text { Nazaré } \\
\text { do Baixo }\end{array}$ & $\begin{array}{l}\text { Nazaré } \\
\text { do Alto }\end{array}$ & $\begin{array}{l}\text { Monte } \\
\text { Carmelo }\end{array}$ & $\mathbf{F A}^{1}$ & FR $(\%)^{2}$ \\
\hline \multicolumn{8}{|c|}{ Já teve algum problema ambiental nos últimos dois anos em sua propriedade, comunidade ou região. } \\
\hline Sim & 25 & 7 & 15 & 13 & 5 & 65 & $100 \%$ \\
\hline Não & 0 & 0 & 0 & 0 & 0 & 0 & $0 \%$ \\
\hline \multicolumn{8}{|c|}{ Quais problemas ambientais você já observou nos últimos dois anos em sua propriedade, comunidade ou região. } \\
\hline Assoreamento dos igarapés & 5 & 0 & 8 & 10 & 0 & 23 & $35 \%$ \\
\hline Polução por lixo doméstico. & 7 & 0 & 3 & 3 & 0 & 13 & $20 \%$ \\
\hline Polução do por agrotóxico & 5 & 7 & 14 & 11 & 5 & 42 & $65 \%$ \\
\hline Polução por efluente industrial & 24 & 7 & 15 & 13 & 5 & 64 & $98 \%$ \\
\hline Desmatamento & 2 & 5 & 9 & 10 & 0 & 26 & $40 \%$ \\
\hline Mudanças climáticas & 25 & 7 & 15 & 13 & 5 & 65 & $100 \%$ \\
\hline \multicolumn{8}{|c|}{ Sobre a empresa você já teve algum problema de relação pessoal com trabalhadores da empresa de dendê } \\
\hline Sim & 5 & 7 & 6 & 7 & 5 & 30 & $46 \%$ \\
\hline Não & 20 & 0 & 9 & 6 & 0 & 35 & $54 \%$ \\
\hline \multicolumn{8}{|c|}{ A empresa tem ajudado os camponeses da comunidade } \\
\hline Sim & 11 & 0 & 4 & 7 & 1 & 23 & $35 \%$ \\
\hline Não & 0 & 7 & 2 & 1 & 3 & 13 & $20 \%$ \\
\hline Mais ou menos & 14 & 0 & 9 & 5 & 1 & 29 & $45 \%$ \\
\hline \multicolumn{8}{|c|}{$\begin{array}{l}\text { A contaminação dos igarapés por efluentes, resíduos e agrotóxicos foi o principal problema que a empresa trouxe } \\
\text { aos camponeses agricultores de sua comunidade. }\end{array}$} \\
\hline Sim & 22 & 7 & 15 & 13 & 4 & 61 & $94 \%$ \\
\hline Não & 3 & 0 & 0 & 0 & 1 & 4 & $6 \%$ \\
\hline
\end{tabular}

${ }^{1}$ FA. Frequência absoluta. ${ }^{2}$ FR. Frequência relativa.

Fonte: Coleta de campo.

De acordo com os entrevistados, a partir da implantação de grandes fazendas de dendeicultura a paisagem vem se modificando e com a construção da indústria surgiram os impactos decorrente dos resíduos produzido na mesma, e a vida dos agricultores já não é mais a mesma como antes. O cultivo e a agroindústria de óleo de palma geram grandes quantidades 
de resíduos lignocelulósicos e efluente. Durante o ciclo de vida dessa palmeira, apenas 10\% é convertida em óleos de palma e palmiste; o restante, $90 \%$ são resíduos gerados durante o manejo e processamento (Atnaw et al., 2014), que podem ser matéria-prima para outras aplicações.

Os manejos das plantas nas fazendas geram folhas (OPF - Oil Palm Fronds) e troncos (OPT - Oil Palm Trunks). Enquanto o beneficiamento dos cachos de frutos frescos (FFB) nas APOs geram biomassas lignocelulósicos residuais, tais como cachos vazios (EFBEmpty Fruit Bunches), fibra do endocarpo prensada (PPF- Pal Pressed Fibres), torta de palmiste (Kernel Shells) e o efluente líquido (POME- Palm Oil Mill Effluent) (Sudirman et al., 2011). Segundo Garcia-Nunez et al. (2015), a biomassa sólida residual gerada na agroindústria de palma de óleo (APO) é cerca de duas vezes ao CPO produzido. De acordo com estes autores estas biomassas residuais estão disponíveis e geradas nas APOs durante todo ano, gerando preocupações econômicas e ambientais, quanto a destinação destes resíduos ou subprodutos.

Em relação a indústria ou usina da empresa de dendê que foi construída no município de Acará, começou a funcionar em novembro de 2015, e funciona continuamente 24 horas por dia, tem capacidade de processar 150 mil toneladas por horas de CFF "Cachos de Frutos Frescos". Produzindo assim, constantemente uma grande quantidade de efluente e demais resíduos. Linwang (2003) cita vários problemas que precisam ser resolvidos para melhor indicação do uso do efluente de dendê para fertilização do solo para plantação, recomenda cuidados na quantidade e na frequência de aplicação de modo a não causar danos ao meio ambiente, para que não venha a acontecer segundo estudos e pesquisas feita na Malásia, o qual é um o país, maior produtor de dendê:

O poder poluidor do efluente é tão grande, que na Malásia maior produtor mundial de dendê, foi estimado que uma usina, com capacidade para processar 20 toneladas de cachos por hora, produz uma quantidade de efluente capaz de poluir o equivalente a uma cidade de 200 mil habitantes. Também foi estimado que a quantidade total de efluente produzido nas usinas malasianas possui um potencial poluidor equivalente ao de uma população de 32 milhões de habitantes, isto é, duas vezes e meia a população do País (Ferreira, 1998, p. 08).

Podemos relacionar que somente a usina de Acará produz quase oito vezes mais que a usina pesquisada na Malásia, e isso vem preocupando moradores das comunidades circo vizinhas a usina, e até das cidades próximas no caso deste estudo a cidade sede do município de Acará, a qual fica a localizada a poucos quilômetros de distância cerca de mais ou menos 
$20 \mathrm{~km}$, subindo o leito do rio Acará-Miritipitanga, ou se for pela estrada tem a distância de 29 km, indo pela PA 252 Acará-Moju km 14, adentrando $15 \mathrm{~km}$ no ramal do Cravo, na fazenda Vale Verde, as margens do rio Acará-Miritipitanga.

A presente pesquisa buscou apresentar o perfil de comunidades próximas a agroindústria de dendê para analisarmos como está a relação de desenvolvimento sustentável dessas comunidades rurais do município de Acará nordeste do estado do Pará, as quais estão sentindo danos, causados pelos efluentes produzidos pela agroindústria de óleo de palma de dendê, para que possamos minimizar possíveis ameaças ao meio ambiente. Este tipo de adequação se faz necessário por ir ao encontro do que é pregado pela indústria dos bicombustíveis: redução dos impactos ambientais.

Pesquisas apontam que 1 hectare com 148 plantas adultas retira, em média por ano, 192,5 kg de N, 26,0 kg de P, 251,4 kg de K, 61,3 kg de Mg e 99,3 kg de Ca, para crescimento, para formação das inflorescências masculinas, e nas coletas dos cachos (Furlan Júnior, 2006; 1998). Como a grande maioria dos solos da Amazônia é de baixa fertilidade, aliado ao fato de o dendezeiro, na Amazônia, estar sendo cultivado principalmente, nos solos da classe dos latossolo, que são os mais representativos da região onde ocupam, aproximadamente, $45 \%$ da área, há necessidade de aplicar grandes quantidades de fertilizantes, que sejam suficientes para sustentar a produtividade da planta e repor os nutrientes extraídos pela mesma ao sistema para maior produtividade (Macedo \& Rodrigues, 2000).

A riqueza do efluente em nutrientes torna-se para a empresa uma ótima opção para ser empregado como fertilizante orgânico e seu retorno ao campo é de extrema importância por reduzir os custos de produção, diminuindo as necessidades de fertilizantes químicos. Entretanto, as empresas não estão levando em conta que com o aumento da produção da dendeicultura aumenta também a produção de efluentes e se for lançado em grande quantidade nas fazendas sem tratamento, acaba por sua vez, afetando os cursos d'águas das áreas, impactando na biodiversidade e consequentemente na vida de agricultores que moram em torno desses grandes plantios de dendê. É o caso das comunidades em estudos que abriga um grande número de pessoas que estão se sentindo impactadas pela poluição causada pelos efluentes que são lançados nas fazendas de dendê do polo agrícola Vera Cruz, da empresa de dendê em Acará.

Esta situação tem prejudicado a saúde de moradores e do ecossistema da área, afetando até mesmo a economia local, pois impossibilita o uso dos recursos hídricos pelas pessoas e principalmente para dá de beber aos animais que consomem diretamente estas águas para sua sobrevivência. Um total de $99 \%$ dos moradores entrevistados relatou que os igarapés 
da área estão poluídos por efluentes despejados que popularmente é conhecido como “tibornia". Eles alegam que antes consumiam água dos igarapés Arapiranga-Açú e Ipitinga, mais que a partir do ano de 2016 começaram a perceber alterações no odor e cor da água dos igarapés. Além disso, presenciaram ocorrência de peixes mortos, surgimento de casos de alergia e doenças estomacais em pessoas que beberam ou tomaram banho nos igarapés da região.

Por isso, todos os moradores das comunidades estudadas começarão a perfurar poços artesianos em suas casas. Eles realizaram inúmeras reuniões com lideranças do poder público, e com representantes da indústria local, para apontarem os riscos causados contaminação nos igarapés. Vale destacar, que tais representantes prometeram a construção de poços e a instalação de uma rede de abastecimento de água nas comunidades, o que não se concretizou até o momento.

Durante desta pesquisa, observamos que nenhum morador consumiu a água dos igarapés, pois estes passaram a utilizar a água dos seus próprios poços artesianos. Entretanto, alguns moradores não tiveram as devidas orientações sobre a construção dos poços, levando em consideração localização das fossas assépticas dos banheiros. Foi observado que a maioria dos poços tem menos de quinze metros de distância das fossas, ocorrendo em risco de contaminação da água.

\section{Considerações Finais}

Constatou-se que a expansão do monocultivo do dendê na região do Acará provoca elevados custos sociais, econômicos e ambientais para as comunidades locais. Foi evidenciada a degradação exacerbada do meio ambiente, fruto da exploração predatória das riquezas naturais dessa região da Amazônia. Tais fatores acarretaram perdas e danos irreversíveis ao meio ambiente e atingindo organizações sociais, os povos tradicionais, nos seus espaços territoriais e na diversidade dos ecossistemas amazônicos.

As principais razões para isso são o despejo descontrolado de agrotóxicos, resíduos e efluentes produzidos pela agroindústria de dendê, em maior escala, e da população local, em menor escala. As consequências disso são: prejuízos na produção de mandioca, criação de animais que utilizam a água para beber, aumento de doenças epiteliais, entre outros.

Foi observado que a população das comunidades segue os pressupostos da agricultura familiar, com mão de obra do grupo familiar e uma cultura diversificada, de mandioca, milho, arroz, açaí, cupuaçu e pimenta do reino. Além da criação de alguns animais 
para alimentação como galinhas e porcos. Essa diversificação na produção e cultivo atenua para os debates da Agroecologia como estratégia do desenvolvimento rural sustentável no enfretamento e resistência dos avanços das empresas monocultoras multinacionais de dendeicultura.

Neste contexto, é preciso valorizar os saberes tradicionais, e enfatiza-se que as instituições, líderes governamentais e os empreendimentos precisam equilibrar o comprometimento social e ambiental com o econômico, com responsabilidade sobre os pressupostos administrativos e diante das consequências que podem gerar a sociedade. Além disso, as sanções devem ser cumpridas de forma rigorosa, nos casos do não cumprimento da legislação ambiental.

Com base nisso, é importante fomentar as discussões sobre os pressupostos da Agroecologia para efetivar o debate sobre o desenvolvimento rural sustentável, e reafirmar a relevância das comunidades tradicionais no contexto da interação com o meio ambiente, pois tem uma relação equilibrada com os ecossistemas. Assim, garantindo às futuras gerações os benefícios que a natureza pode oferecer as populações dessas comunidades. Como trabalhos futuros, sugerimos a realização de capacitações em técnicas de tratamento de resíduos sólidos e de efluentes nessas comunidades, com o objetivo de mitigar os impactos ambientais observados no presente estudo.

\section{Agradecimentos}

À Universidade Federal do Pará (UFPA) por esse trabalho de conclusão do Curso de Graduação em Educação do Campo. Aos moradores das comunidades pela colaboração da pesquisa realizada.

\section{Referências}

Abrapalma. (2014). Planilha de mapeamento da palma de óleo no Brasil. Associação Brasileira de Produtores de Óleo de Palma. 2014.

Ahlert, EM. (2015). Sistema de indicadores para avaliação da sustentabilidade de propriedades produtoras de leite. Dissertação (Mestrado em Ambiente e Desenvolvimento). Universidade do Vale do Taquari, Lajeado. 
Alves, RNB \& Cardoso, CEL. (2008). Sistemas e custo de produção de mandioca desenvolvido por pequenos agricultores familiares do município de Moju, PA. Belém: Embrapa Amazônia Oriental. (Comunicado Técnico n. 210).

Atnaw, SM, Sulaiman, SA \& Yusup, S. (2014). Influence of fuel moisture content and reactor temperature on the calorific value of syngas resulted from gasification of oil palm fronds. The Scientific World Journal, p. 1-10. http://dx.doi.org/10.1155/2014/121908

Belttame, SAB. (2000). Professoras e professores do MST: sujeitos em movimento. Tese de doutorado, USP São Paulo.

Brito, JGS \& Maciel, B. (2015). Agricultura familiar e associativismo: o caso da Associação das Mulheres Empreendedoras Rurais de Palmeira em Glória do Goitá- PE. Questões controversas do mundo contemporâneo, 9(1). Disponível em: http://humanae.esuda.com.br/index.php/humanae/article/view/203. Acesso em: 11/05/2020.

Caldas, MM, Walker, R, Shirota, R, Perz, S \& Skole, D. (2003). Ciclo de vida da família e desmatamento na Amazônia: combinando informações de sensoriamento remoto com dados primários. Revista Brasileira de Economia, 57(4). https://doi.org/10.1590/S003471402003000400002

Cavalheiro, CN, Rempel, C, Laroque, LFS \& Machado, BNB. (2014). Perfil socioeconômico e análise da qualidade de vida dos produtores de leite da comunidade São Justino, em Juína/MT. Revista Destaques Acadêmicos, 6(3), 149-156.

Chaves. GP \& Magalhães, SB. (2016). Percepção de riscos e implicações sociais: ema analise sobre o uso de agrotóxicos por camponeses, integrandos à agroindústria do dendê no estado do Pará.

Cruz, RHR. (2018). Impactos socioambientais de produção de palma de dendê na Amazônia paraense: uso de agrotóxicos e poluição ambiental nas sub-bacias hidrográficas, Tailândia (PA). Dissertação de Mestrado do Programa de Pós-Graduação em Gestão de Recursos Naturais e Desenvolvimento Local da Amazônia. Universidade Federal do Pará, Núcleo de Meio ambiente. 
Ferreira, WA, Botelho, SM \& Vilar, RRL. (1998). Uso do Efluente da Agroindústria do Dendê como Adubo Orgânico em Latossolo Amarelo Álico Textura Média. 1- Efeito Sobre o $\mathrm{Ph}, \mathrm{P}$ e Al. Empresa Brasileira de Pesquisa Agropecuária 22p. Disponível em: https://www.embrapa.br/busca-de-publicacoes/-/publicacao/375582/uso-do-efluente-daagroindustria-do-dende-como-adubo-organico-em-latossolo-amarelo-alico-textura-media-1efeito-sobre-o-ph-p-e-ai. Acesso em: 11/05/2020..

Fraxe, TJP. (2004). Cultura cabocla ribeirinha. Mitos, lendas e transculturalidade. São Paulo: Annablume, p. 191.

Furlan Jr, J. (2006). Dendê: manejo e uso dos subprodutos e dos resíduos. Embrapa Amazônia Oriental, 29p. Disponível em:

https://www.infoteca.cnptia.embrapa.br/infoteca/bitstream/doc/391512/1/Doc.246.pdf. Acesso em: 11/05/2020.

Garcia-Nunez, J. (2015). A.Evolution of Palm Oil Mills into Biorefineries, Washington State University, Ph.D. dissertation

Homma, AKO. (2016). Cronologia do cultivo do dendezeiro na Amazônia. Embrapa Amazônia Oriental, 2016. Disponível em:

https://www.infoteca.cnptia.embrapa.br/infoteca/bitstream/doc/1056562/1/DOC423Ainfo.pdf. Acesso em: 11/05/2020.

Homma, AKO \& Vieira, ICG. (2012). Colóquio sobre Dendezeiro: Prioridades de pesquisa econômica, sociais e ambientais na Amazônia. Amazônia: Cia. \& Desenv, 8(15). Disponível em: https://ainfo.cnptia.embrapa.br/digital/bitstream/item/90943/1/R-15-Coloquio-SobreDendezeiro.pdf. Acesso em: 11/05/2020.

Instituto Evandro Chagas. (2004). Instituto Evandro Chagas detecta contaminação por agrotóxicos na Região de Expansão do Dendê. 2004. Disponível em: https://reporterbrasil.org.br/2014/09/instituto-evandro-chagas-detecta-contaminacao-poragrotoxicos-na-regiao-de-expansao-do-dende-no-para/. Acesso em: 11/05/2020. 
Liwang, T. (2003). Spotlight on PT SMART. Palm oil mill effluent management. BUROTROP Bulletin, Montpellier, 19(38).

Macêdo, J. L. V., \& Rodrigues, M. R. (200). Solos da Amazônia e cultivo do dendezeiro. In: Viégas, I. J. M., Müller, A. A. A cultura do dendezeiro na Amazônia Brasileira. Belém: Embrapa Amazônia Oriental/Manaus: Embrapa Amazônia Ocidental, p.73-88.

Maneschy, M. C. (1995). “Pescadoras em busca de cidadania”. IN; Alvares, M. L. M; D’Incao, M. Â. (org) A mulher existe? Uma contribuição ao estudo da mulher e gênero na Amazônia. Belém: GEPEM.

Marconi, M. A., \& Lakatos, E. M. (2010). Técnicas de pesquisas: Planejamento e execução de pesquisas, amostragens e técnicas de pesquisas, elaboração, análise e interpretação de dados. 3 Ed. São Paulo: Atlas.

Mynaio, M. C. S. (2004). O desafio do conhecimento: pesquisa quantitativa em saúde. 8. Ed. São Paulo: Hucitec.

Nahum, J. S. (2011). De Ribeirinhos a Quilombola: dinâmica territorial de comunidade rurais na Amazônia paraense. Campo território: revista de geografia, 6(1), 79-103. Disponível em: http://www.seer.ufu.br/index.php/campoterritorio/article/view/13470/7694. Acesso em: 11/05/2020.

Nahum, J. S., \& Santos, C. B. (2013). Impactos socioambientais da dendeicultura em comunidades tradicionais na Amazônia paraense. Acta Geográfica, 63-80. https://doi.org/10.5654/actageo2013.0003.0004

Pagliarussi, M. S. (2010). A cadeia produtiva agroindustrial do açaí: estudo da cadeia e proposta de um modelo matemático. 65f. 2010. Trabalho de Conclusão de Curso (graduação em Engenharia de Produção) - Escola de Engenharia de São Carlos, Universidade de São Paulo.

Passos, B. (2002). Maré Grande no vale do Acará, outubro $2^{\mathrm{a}}$ Edição Brasília -DF. 
Pereira, AS, Shitsuka, DM, Parreira, FJ \& Shitsuka, R. (2018). Metodologia da pesquisa científica. [e-book]. Santa Maria. Ed. UAB/NTE/UFSM. Disponível em: https://repositorio.ufsm.br/bitstream/handle/1/15824/Lic_Computacao_MetodologiaPesquisa-Cientifica.pdf?sequence $=1$.

Reporte Brasil. (2013). Relatório inédito aponta os custos da expansão do dendê no nordeste do Pará. Disponível em: https://reporterbrasil.org.br/2013/06/relatorio-inedito-aponta-oscustos-da-expansao-de-dende-no-nordeste-do-para/. Acesso em: 11/05/2020.

Sales, MNG. (2005). Criação de galinhas em sistemas agroecológico. Vitória ES. Incaper. Santos, LF, Campos, APT \& Ferreira, MAM. (2017). Barreiras do desempenho em cooperativas da agricultura familiar e suas implicações para o acesso às políticas públicas. Anais... IV Encontro Brasileiro de Administração Pública, João Pessoa.

Silva, FNL, Moraes, TM, Brito, TP \& Costa, LCO. (2011). A atividade de pesca desenvolvida pela comunidade de Igarapé Açu, Nordeste Do Pará, Brasil. Anais... XVII Congresso Brasileiro de Engenharia de Pesca.

Soares, CMT, Hort, JV \& Basso, RBD. (2019). A percepção do cooperativismo pelos agricultores familiares associados da cooperativa mista agrofamiliar de Vera Cruz do Oeste A Tulha. Revista Orbis Latina, 9(1). https://revistas.unila.edu.br/index.php/orbis

Souza, MA. (2006). Educação do Campo: propostas e práticas pedagógicas do MST. Petrópolis RJ: Vozes.

Svdirman, UL, Sutrlsna, A, Ustiyowati, S, Fadu, L, Arlgan, BT. (2011). The potency of oil palm plantation wastes for mushroom production. Anais... Proceedings of the 7 th International Conference on Mushroom Biology and Mushroom Products (ICMBMP7), p. 378-384. Disponível em: https://repository.ipb.ac.id/bitstream/handle/123456789/56530/proceeding\%20mushrom\%20b iologi\%20\%28lisdar\%29.pdf?sequence=1\&isAllowed=y. Acesso em: 11/05/2020.

UNFPA. (2015). População e desenvolvimento sustentável na Amazônia. Brasília: UNFPA Fundo de População das Nações Unidas. 
Venturieri, A, Fernandes, WR, Boari, AJ \& Vasconcelos, MV. (2009). Relação entre ocorrência do amarelecimento fatal do dendezeiro (Elaeis guineensis) e variáveis ambientais no estado do Pará. Anais... Simpósio Brasileiro de Sensoriamento Remoto, Natal, INPE, P. 523-530.2009. Disponível em: https://www.embrapa.br/busca-de-publicacoes/-

/publicacao/658494/relacao-entre-ocorrencia-do-amarelecimento-fatal-do-dendezeiro-elaeisguineensis-jacq-e-variaveis-ambientais-no-estado-do-para. Acesso em: 11/05/2020.

Zar, JH. (1999). Biobstatistical Analysis. 4 th Editinon, Prentice Hall, Upper Saddle River.

\section{Porcentagem de contribuição de cada autor no manuscrito}

José Augusto dos Santos Batista - 40\%

Mayane de Souza Barbosa - 25\%

Fabricio Nilo Lima da Silva - 20\%

Luã Caldas de Oliveira - 10\%

Ronaldo Lopes de Sousa - 05\% 